\title{
Prognostic Factors in Operated Stage IIIC, Pathological N3a Breast Cancer Patients
}

\author{
Ibrahim Turkera Ulku Y. Arslan ${ }^{a}$ Ozan Yazicib Ummugul Uyeturk ${ }^{\mathrm{b}}$ Berna Oksuzoglua \\ Burcin Budakoglu ${ }^{a}$ Nuriye Özdemir ${ }^{b}$ Ozlem U. Sonmez ${ }^{d}$ Kaan Helvacia Onur Esbah ${ }^{a}$ \\ Oznur Bal $^{\mathrm{a}}$ Ahmet S. Ekincia Nurullah Zengin ${ }^{\mathrm{b}}$
}

aMedical Oncology Department, Dr. Abdurrahman Yurtaslan Oncology Training and Research Hospital, Ankara, Turkey

bMedical Oncology Department, Ankara Numune Training and Research Hospital, Turkey

'Medical Oncology Department, Faculty of Medicine, Abant Izzet Baysal University, Bolu, Turkey

dMedical Oncology Department, Faculty of Medicine, Yeditepe University, Istanbul, Turkey

\section{Keywords}

Breast cancer - Lymph node metastasis .

Prognostic factor - Survival · Treatment strategies

\section{Summary}

Background: The aim of this retrospective study was to evaluate the prognostic factors in patients operated for stage IIIC breast carcinoma who had > 10 positive axillary lymph nodes (pN3a). Patients and Methods: The medical records of 302 operated N3a breast cancer patients without distant metastasis followed up in 2 medical oncology clinics in Ankara between January 1998 and June 2013 were evaluated retrospectively. Results: The median age was $50(21-83)$ years. The median follow-up time was 43 (5-191) months. The patients were divided into 4 subgroups according to hormone receptor (HR) and human epidermal growth factor receptor 2 (HER2) status. There were $151(50.0 \%)$ patients in the HR+/HER2- group, 80 (26.5\%) patients in the HR+/HER2+ group, $42(13.9 \%)$ patients in the HR-/HER2+ group, and $29(9.6 \%)$ patients in the triple negative (TN) group. At the time of analysis, 155 (51.3\%) patients had recurrent disease and 117 (38.7\%) patients had died. The median disease-free survival (DFS) and overall survival (OS) times were 46.0 and 78.0 months, respectively. Both the DFS and OS in the HR+/HER2- group were longer than in the other groups (log-rank $p=0.034$ and $p=0.016$, respectively). Menopausal status, progesterone receptor (PgR) status, and lymph node ratio (LNR; defined as the number of positive lymph nodes compared to the total number of removed lymph nodes) were found to be independent prognostic factors $(p=0.019, p=0.001$, and $p$ $=0.012$, respectively). Conclusion: Menopausal status,
PgR status, and LNR were independent prognostic factors in operated N3a breast cancer patients, who are underrepresented in breast cancer trials.

\section{Introduction}

Breast cancer (BC) is the most common cancer among Turkish women [1]. There is a certain percentage of women who are still diagnosed at a later stage in Turkey [2].

The disease stage is an important clinical prognostic factor affecting both the disease-free survival (DFS) and the overall survival (OS) in BC [3]. Tumor size and nodal metastasis were significantly correlated to its malignant capacity [4]. According to molecular studies, there are at least 5 molecular subtypes with variable prognosis [5]. However, in routine clinical practice, BC subtypes are not determined by microarray, but surrogate markers such as the estrogen receptor (ER), progesterone receptor $(\mathrm{PgR})$, and human epidermal growth factor receptor 2 (HER2) status are frequently used in the decision on the optimal treatment.

There is no prospective study to evaluate the prognosis of operable stage IIIC BC depending on its subtypes. These patients constitute only a small subset of the study population in large-scale prospective BC trials [6]. Retrospective studies usually have nonhomogeneous patient populations [7-10]. A recent study noted that, unlike early recurrence, the tumor biology may have a more important role than the tumor load (positive lymph nodes) for late recurrence in ER-positive disease $[11,12]$. The aim of this retrospective study was to evaluate the prognostic factors in operated stage IIIC, pN3a BC patients.

\section{KARGER \\ Fax +497614520714 \\ Information@Karger.com}

www.karger.com (c) 2014 S. Karger GmbH, Freiburg

$1661-3791 / 14 / 0096-0421 \$ 39.50 / 0$

Accessible online at:

www.karger.com/brc 
Table 1. Basic characteristics of the patients

\begin{tabular}{|c|c|}
\hline Characteristic & $\mathrm{n}(\%)$ \\
\hline Median age, years & $50(21-83)$ \\
\hline$<40$ years & $55(18.2 \%)$ \\
\hline $40-49$ years & $92(30.5 \%)$ \\
\hline $50-59$ years & $90(29.8 \%)$ \\
\hline$\geq 60$ years & $65(21.5 \%)$ \\
\hline \multicolumn{2}{|l|}{ Menopausal status } \\
\hline Premenopausal & $157(52.0 \%)$ \\
\hline Postmenopausal & $145(48.0 \%)$ \\
\hline \multicolumn{2}{|l|}{ Type of histology } \\
\hline Invasive ductal & $264(87.4 \%)$ \\
\hline Invasive lobular & $18(6.0 \%)$ \\
\hline Mixed & $11(3.6 \%)$ \\
\hline Others & $9(3.0 \%)$ \\
\hline \multicolumn{2}{|l|}{ Grade of histology } \\
\hline I & $13(4.3 \%)$ \\
\hline II & $110(36.4 \%)$ \\
\hline III & $152(50.3 \%)$ \\
\hline Unknown & $27(8.9 \%)$ \\
\hline \multicolumn{2}{|l|}{ Tumor size } \\
\hline I & $23(7.6 \%)$ \\
\hline II & $145(48.0 \%)$ \\
\hline III & $121(40.1 \%)$ \\
\hline IV & $13(4.3 \%)$ \\
\hline \multicolumn{2}{|l|}{ ER status } \\
\hline Positive & $218(72.2 \%)$ \\
\hline Negative & $84(27.8 \%)$ \\
\hline \multicolumn{2}{|l|}{ PgR status } \\
\hline Positive & $183(60.6 \%)$ \\
\hline Negative & $119(39.4 \%)$ \\
\hline \multicolumn{2}{|l|}{ HER2 status } \\
\hline Positive & $122(40.4 \%)$ \\
\hline Negative & $180(59.6 \%)$ \\
\hline \multicolumn{2}{|l|}{ Subgroups } \\
\hline HR+/HER2- & $151(50.0 \%)$ \\
\hline $\mathrm{HR}+/ \mathrm{HER} 2+$ & $80(26.5 \%)$ \\
\hline HR-/HER2+ & $42(13.9 \%)$ \\
\hline $\mathrm{TN}$ & $29(9.6 \%)$ \\
\hline Metastatic lymph nodes & $15(10-53)$ \\
\hline $10-15$ & $159(52.6 \%)$ \\
\hline$>16$ & $143(47.4 \%)$ \\
\hline Dissected lymph nodes & $23(10-60)$ \\
\hline Lymph node ratio, median (range) & $0.75(0.18-1.0)$ \\
\hline$\leq 0.75$ & $157(52.0 \%)$ \\
\hline$>0.75$ & $145(48.0 \%)$ \\
\hline
\end{tabular}

$\mathrm{ER}=$ estrogen receptor, $\mathrm{PgR}=$ progesterone receptor, HER2 = human epithelial growth factor receptor 2, $\mathrm{HR}=$ hormone receptor, $\mathrm{TN}=$ triple negative.

\section{Patients and Methods}

Among 3,297 women with BC followed up in 2 medical oncology clinics in Ankara between January 1998 and June 2013, 302 operated BC patients with $\geq 10$ involved axillary lymph nodes were included in this retrospective study. None of these cases had received neoadjuvant systemic therapy. The clinicopathologic data were collected through examination of the medical records of the patients. The ER and PgR status were deter- mined by immunohistochemistry (IHC) and both of them were avaible for all patients. Since the Ki-67 proliferation index was not studied for the large majority of the patients, we used the tumor grade instead.

The patients were divided into 4 subgroups: hormone receptor (HR) positive/HER2 negative (ER+ and/or PgR+, HER2-), HR positive/ HER2 positive (ER+ and/or $\mathrm{PgR}+$, HER2+), HR negative/HER2 positive (ER- and PR-, HER2+), and triple negative (TN; ER-, PgR-, HER2-).

The lymph node ratio (LNR) was previously defined as the number of positive lymph nodes compaired to the total number of removed lymph nodes $[10,11]$. In the present study, we used 0.75 as the cut-off point because the largest DFS and OS differences were found when 0.75 was taken as the cut-off point.

DFS was defined as the time until the first event, including local and regional relapse, distant metastasis, and death. Overall survival (OS) was calculated from the date of diagnosis until death for any reason or the date of last contact.

\section{Statistics}

Fisher's exact test was used to compare the patient characteristics and tumor factors between populations. The Kaplan-Meier method and the log-rank test were used to compare and analyse the survival data. The determination of independent prognostic factors influencing survival was performed by Cox's proportional hazard model. The $95 \%$ confidence interval (CI) was calculated. A p value less than 0.05 was considered to be statistically significant. All statistical analyses were performed with SPSS for Windows, version 15.0 (SPSS Inc., Chicago, IL, USA).

\section{Results}

All patients were women. The median age was $50(21-83)$ years. $157(52.0 \%)$ patients were premenopousal. $87 \%$ of the patients had invasive ductal carcinoma. $262(86.8 \%)$ of the patients had grade 2 or 3 tumors. The proportions of $\mathrm{BC}$ subgroups were as follows: $50.0 \% \mathrm{HR}+/ \mathrm{HER} 2-, 26.5 \% \mathrm{HR}+1$ HER $2+, 13.9 \%$ HR-/HER2+, and $9.6 \%$ TN. The demographic characteristics of the patients are shown in table 1.

$285(94.4 \%)$ of the patients had modified radical mastectomy (MRM). Adjuvant radiotherapy was administered in 280 (92.7\%) patients. All HR-positive patients were treated with adjuvant hormonotherapy. 60 (49.2\%) of the HER2+ patients received adjuvant trastuzumab. Detailed treatment information according to the tumor subgroups is given in table 2 .

\section{Survival Analysis}

The median duration of follow-up was 43.0 (5-191) months. The median DFS and OS were 46.0 (95\% CI: $37.7-$ 54.3 ) and 78.0 (95\% CI: 68.3-87.7) months, respectively.

\section{Disease-Free Survival}

Patients with HR+/HER2- status had a significantly longer 5-year DFS than the HR+/HER2+ and HR-/HER2+ groups $(49.2 \%, 31.2 \%$, and $19.1 \%$, respectively; $\mathrm{p}=0.034)$, but we did not find any significant differences between the TN patients and the other groups according to DFS. The DFS curves by tumor subgroup are displayed in figure 1a. Treatment with an adjuvant aromatase inhibitor in the postmenopausal HR+ 
Table 2. Treatment characteristics of the patients according to tumor subgroup

\begin{tabular}{|c|c|c|c|c|c|}
\hline Adjuvant chemotherapy & $\begin{array}{l}\text { HR+/HER2-, } \\
\mathrm{n}=151(50 \%)\end{array}$ & $\begin{array}{l}\text { HR+/HER2+, } \\
\mathrm{n}=80(26.5 \%)\end{array}$ & $\begin{array}{l}\text { HR-/HER2+, } \\
\mathrm{n}=42(13.9 \%)\end{array}$ & $\begin{array}{l}\mathrm{TN}, \mathrm{n}=29 \\
(9.6 \%)\end{array}$ & $\begin{array}{l}\text { Total, n }(\%) \\
(100 \%)\end{array}$ \\
\hline Antracycline & $22(7.3 \%)$ & $8(2.6 \%)$ & $4(1.3 \%)$ & $4(1.3 \%)$ & $38(12.6 \%)$ \\
\hline Antracycline-taxane & $123(40.7 \%)$ & $37(12.3 \%)$ & $16(5.3 \%)$ & $25(8.3 \%)$ & $201(66.6 \%)$ \\
\hline Antracycline-taxane and trastuzumab & - & $32(10.6 \%)$ & $20(6.6 \%)$ & - & $52(17.2 \%)$ \\
\hline CMF & $4(1.3 \%)$ & - & $2(0.7 \%)$ & - & $6(2.0 \%)$ \\
\hline \multicolumn{6}{|l|}{ Adjuvant hormone therapy ( $\%$ of $\mathrm{HR}+$ ) } \\
\hline $\operatorname{Tmx}$ & $65(29.5 \%)$ & $34(15.5 \%)$ & & & $99(45.0 \%)$ \\
\hline AI & $33(15.0 \%)$ & $28(12.7 \% 9$ & & & $61(27.7 \%)$ \\
\hline Switch (Tmx to AI) & $20(9.1 \%)$ & $9(4.1 \%)$ & & & $29(13.2 \%)$ \\
\hline Extended adjuvant & $5(2.3 \%)$ & - & & & $5(2.3 \%)$ \\
\hline Tmx + LHRH agonists & $21(9.5 \%)$ & $5(2.3 \%)$ & & & $26(11.8 \%)$ \\
\hline \multicolumn{6}{|l|}{ Adjuvant trastuzumab ( $\%$ of HER $2+$ ) } \\
\hline Yes & & $37(30.3 \%)$ & $23(18.9 \%)$ & & $60(49.2 \%)$ \\
\hline No & & $43(35.2 \%)$ & $19(15.6 \%)$ & & $62(50.8 \%)$ \\
\hline \multicolumn{6}{|c|}{ First-line palliative chemotherapy (\% of received) } \\
\hline Taxane containing & $20(14.8 \%)$ & $3(2.2 \%)$ & $2(1.5 \%)$ & $3(2.2 \%)$ & $28(20.7 \%)$ \\
\hline Platin doublet & $11(8.2 \%)$ & $1(0.7 \%)$ & - & $5(3.7 \%)$ & $17(12.6 \%)$ \\
\hline Trastuzumab combinations & - & $27(20.0 \%)$ & $14(10.4 \%)$ & - & $41(30.4 \%)$ \\
\hline Hormone therapy & $24(17.8 \%)$ & $3(2.2 \%)$ & - & - & $27(20.0 \%)$ \\
\hline Lapatinib, capecitabine & - & $2(1.5 \%)$ & $4(3.0 \%)$ & - & $6(4.5 \%)$ \\
\hline Others & $11(8.2 \%)$ & $2(1.5 \%)$ & - & $3(2.2 \%)$ & $16(11.9 \%)$ \\
\hline
\end{tabular}

$\mathrm{HR}=$ Hormone receptor, HER2 = human epithelial growth factor receptor 2, TN = triple negative, $\mathrm{CMF}=$ cyclophosphamide/methotrexate/fluorouracil, LHRH = luteinizing hormone-releasing

hormone, $\mathrm{Tmx}=$ tamoxifen, $\mathrm{AI}=$ aromatase inhibitor.

Fig. 1. DFS $(\mathbf{A})$ and OS (B) curves by tumor subgroup. $\mathrm{HR}=$ Hormone receptor,

HER2 = human epithelial growth factor receptor 2 , $\mathrm{n}=$ number of cases included at time 0 and number of cases still under observation at the end of the study.
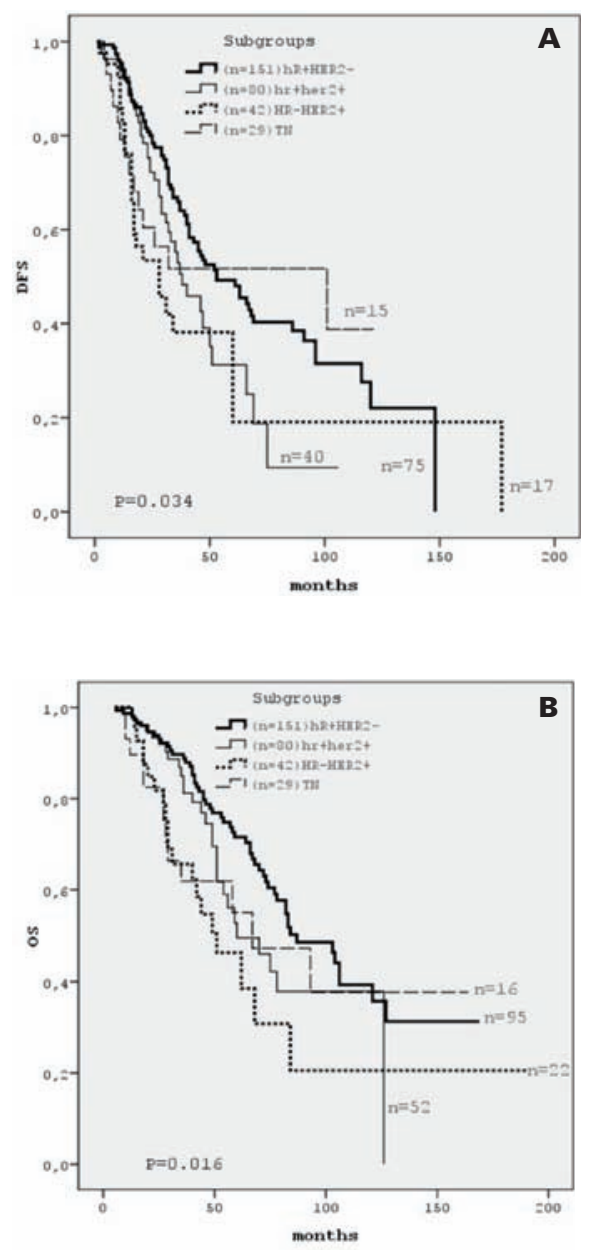

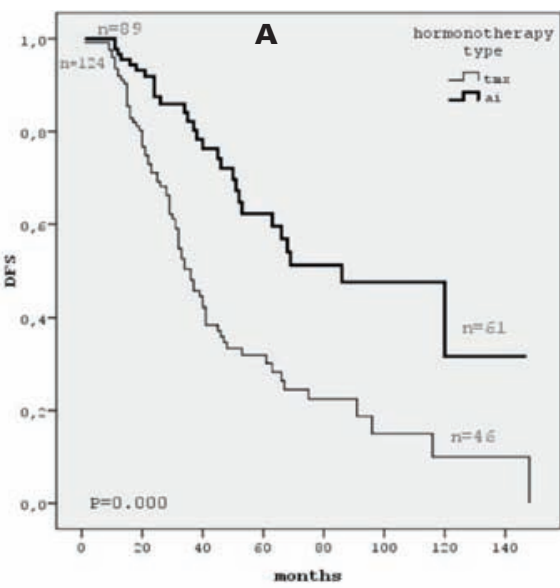

Fig. 2. DFS (A) and OS (B) curves by hormone therapy type. $\mathrm{AI}=$ Aromatase inhibitor,

Tmx = tamoxifen, $\mathrm{n}=$ number of cases included at time 0 and number of cases still under observation at the end of the study.

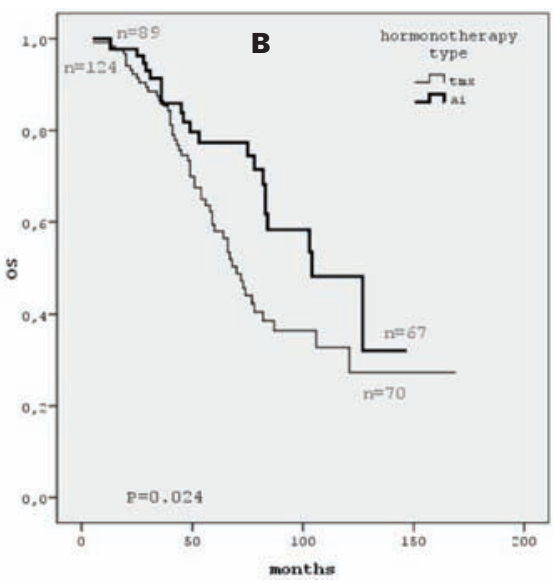




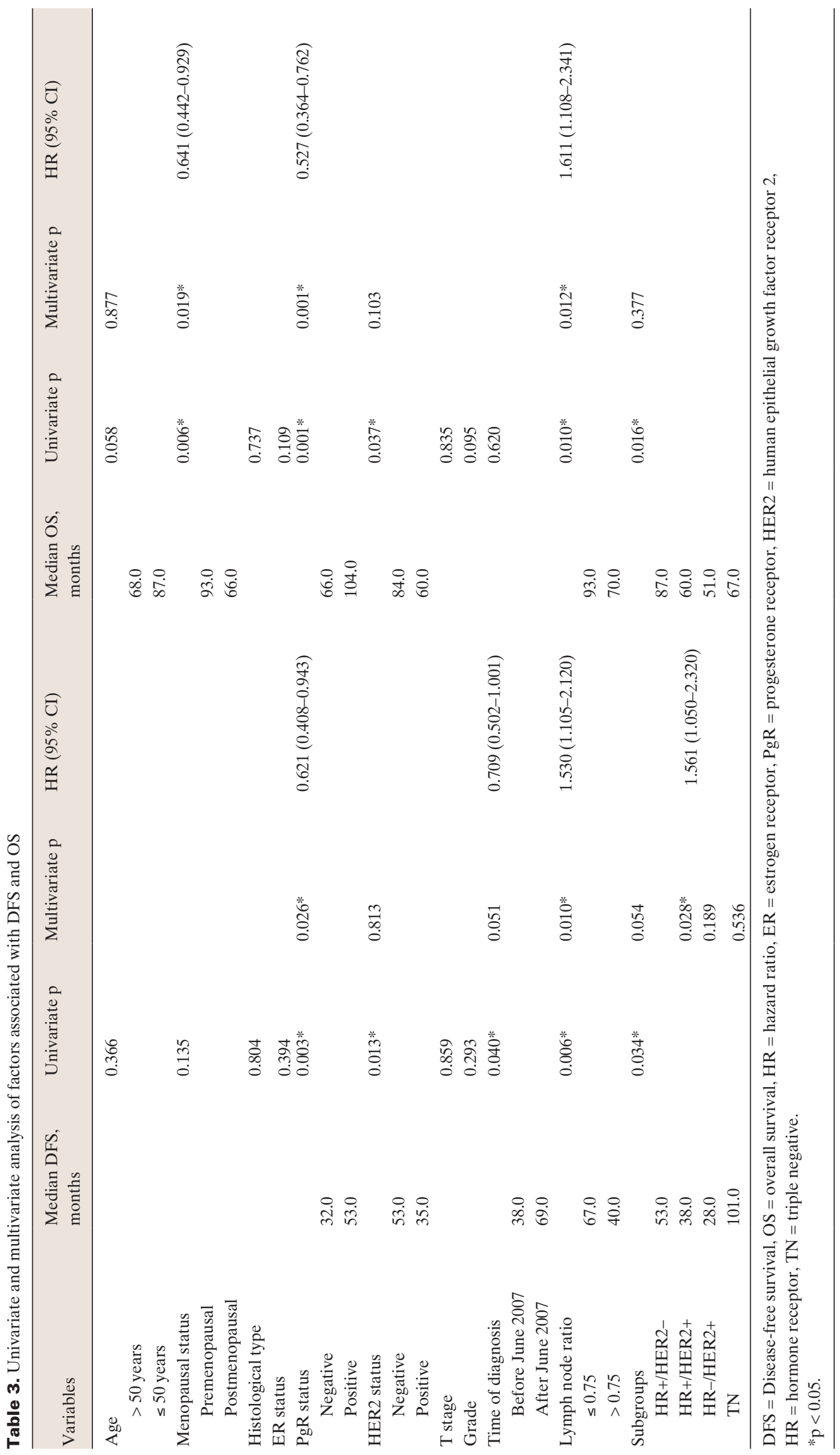


subgroup was correlated with a better DFS than treatment with tamoxifen ( $\mathrm{p}<0.001$; fig. $2 \mathrm{a})$.

Univariate analysis showed that PgR positivity, HER2status, time of diagnosis (after June 2007), and HR+/HER2tumor subgroup were correlated with better DFS $(p=0.003, p$ $=0.013, \mathrm{p}=0.040$, and $\mathrm{p}=0.034$, respectively). We did not find any correlation between age, histology, grade, ER status, surgery type, and DFS (table 3). A higher LNR (LNR > 0.75) was also correlated with worse DFS ( $\mathrm{p}=0.006$; fig. $3 \mathrm{a}$ ).

In multivariate Cox regression analysis, $\mathrm{PgR}$ status ( $\mathrm{p}=$ 0.026, hazard ratio (HR): 0.621, 95\% CI: 0.408-0.943), tumor subgroup ( $\mathrm{p}=0.028$, HR: $1.561,95 \% \mathrm{CI}: 1.050-2.320$ ), and LNR ( $p=0.010$, HR: 1.530, 95\% CI: 1.105-2.120) were found to be independent prognostic factors with a significant influence on the DFS (table 3).

\section{Overall Survival}

Patients with HR+/HER2- staus had a significantly longer 5-year OS rate than HR+/HER2+ and HR-/HER2+ patients (71.5\%, 49.4\%, and 38.5\%, respectively; log-rank $\mathrm{p}=0.016)$. We did not find any significant differences between TN patients and the other groups according to OS. The OS curves by tumor subgroup are displayed in figure $1 \mathrm{~b}$. Treatment with an adjuvant aromatase inhibitor in the postmenopausal HR+ subgroup was correlated with a better OS than treatment with tamoxifen ( $\mathrm{p}=0.024$; fig. $2 \mathrm{~b})$.

Univariate analysis showed that premenopausal status, PgR positivity, HER2- status, and HR+/HER2- tumor subgroup were correlated with a better OS ( $\mathrm{p}=0.006, \mathrm{p}=0.001$, $\mathrm{p}$ $=0.037$, and $\mathrm{p}=0.016$, respectively; table 3 ). We did not find any correlation between histology, grade, ER status, surgery type, and OS (table 3). A higher LNR (LNR > 0.75) was also corralated with worse outcome $(\mathrm{p}=0.010$; fig. $3 \mathrm{~b})$.

In multivariate Cox regression analysis, premenopausal status ( $\mathrm{p}=0.019$, HR: 0.641, 95\% CI: 0.442-0.929), PgR status ( $\mathrm{p}=0.001$, HR: $0.527,95 \%$ CI: 0.364-0.762), and LNR ( $\mathrm{p}=$ 0.012, HR: $1.611,95 \%$ CI: 1.108-2.341) were found to be independent prognostic factors with a significant influence on OS (table 3).

\section{Discussion}

Our centers are tertiary reference centers mostly accepting patients from rural areas of Central Anatolia. We have a high percentage $(10 \%)$ of women diagnosed at later stages of BC.

Women with HR-positive BC have a better prognosis due to a slower growth rate compared to TN tumors [13]. Similarly, we found that the HR+/HER2- group in this cohort lived significantly longer than the HER2+ and TN patients.

Most of the patients in this study have been treated with sequential anthracycline- and taxane-based regimens. Chemotherapy was less efficient for HR+ tumors than for HR- ones [14]. Recent studies noted a higher and earlier peak of recur-

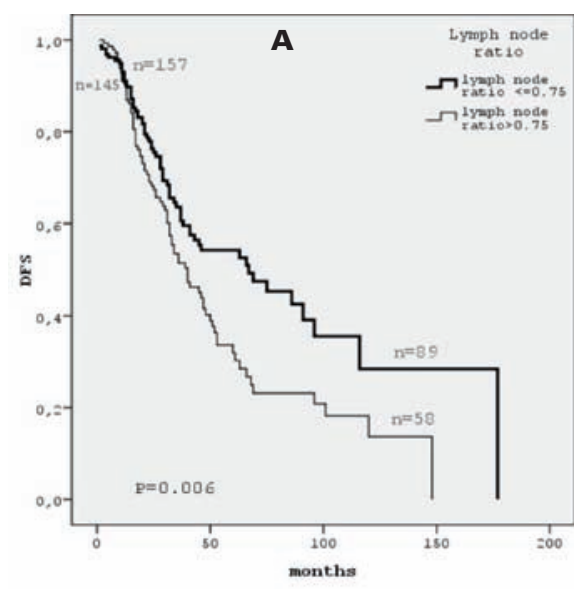

Fig. 3. DFS (A) and OS (B) curves by LNR (number of positive lymph nodes compaired to total number of removed lymph nodes). $\mathrm{n}=$ Number of cases included at time 0 and number of cases still under observation at the end of the study.

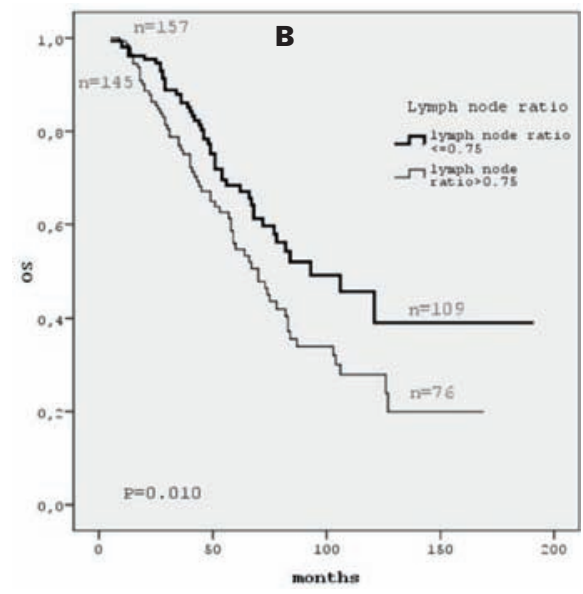

rences in patients receiving tamoxifen [15] than in patients who switched to anastrozole following 2 or 3 years of tamoxifen [16]. An additional 5-year course of letrozole also resulted in improved DFS and OS [16]. In our study, in patients diagnosed with BC before 2004, tamoxifen rather than aromatase inhibitors had been mostly used in postmenopausal women.

As a limitation of our study, the Ki-67 proliferation index results were not available for the large majority of the patients. We thus classified our patients only according to ER, PR, and HER2 status and histological grade. Ferguson et al. [17] suggested using the tumor grade in the absence of the Ki-67 proliferation index in Caucasian women. We also used the tumor grade instead of the Ki-67 proliferation index since the tumor grade was available in $91.1 \%$ of our patients. The percentage of histological grade I cases was only $4.3 \%$ in our patient population, although we double checked the histological stage in both biopsy and mastectomy materials in most cases; we think this might be related to the higher disease stage.

It has been reported that the HER2 positivity rates increase with increasing disease stage [18]. In the current study, the HER 2 positivity rate was $40.4 \%$. This was also consistent 
with a previous retrospective study in Turkey [10]. The proportion of operable stage IIIC BC was approximately $13 \%$ in 2 large randomized adjuvant trastuzumab trials [19, 20]. Trastuzumab has maintained its efficacy after adjustment for nodal status. But it was difficult to interpret these results for stage IIIC patients.

According to a meta-analysis, 1 year of trastuzumab was better than 2 years or 6 months of trastuzumab [21]. Only half of the HER2+ patients received adjuvant trastuzumab in our study because adjuvant trastuzumab had been approved by the Ministary of Health of Turkey in June 2007. The relatively poor outcome of the HER+ subgroup could be explained by inadequate use of adjuvant trastuzumab in our study.

The TN subgroup constitutes less than $10 \%$ of our study population $(\mathrm{n}=29)$. This is consistent with a previous study [22]. The correlation between prognosis and the number of metastatic lymph nodes has not been precisely determined in node-positive TN BC [23]. As opposed to the above-mentioned study, we found relatively better DFS and OS rates. We think this paradoxical clinical outcome might be due to the limited size of our TN patient group.

According to the 13th St Gallen International Breast Cancer Conference, the panel suggested to use a requirement for $\geq 20 \%$ PgR positivity in the definition of 'luminal A-like' cancer and a threshhold of $\geq 20 \% \mathrm{Ki}-67$ status in the definition of 'luminal B-like' cancer, without using molecular tests but on the basis of gene array data [24]. Therefore, the lack of substantial PgR positivity was associated with a less endocrine- sensitive, more aggressive and worse prognostic subtype of $\mathrm{BC}$. We also found that PgR positivity was the strongest independent prognostic factor for both DFS and OS in this patient group. But we did not consider the $\mathrm{PgR}+$ or $\mathrm{PgR}-$ status of HR-positive patients to select different endocrine therapies.

In recent studies, the LNR, which has been defined as 'positive lymph nodes compaired to total removed lymph nodes', has been proposed as a new prognostic tool $[10,25]$. Several cut-off points ranging between 0.2 and 0.9 were found to be related with survival in different studies $[10,25]$. In the present study, the largest DFS and OS differences were found when 0.75 was taken as the cut-off point. We also confirmed that the LNR was an independent prognostic factor for both DFS and OS in our patient group.

In conclusion, $\mathrm{HR}+/ \mathrm{HER} 2-\mathrm{BC}$ patients still have a better prognosis than HER2+ and TN BC patients, even if they had extensive axillary lymph node metastasis. Menopausal status, PgR positivity, and LNR were also independent prognostic factors. Determination of these prognostic factors together with tumor subgroups might be a practical guide for these patients who are underrepresented in BC trials.

\section{Disclosure Statement}

The authors declare that they have no financial relationship regarding the commercial matters and/or no conflict of interest.

\section{References}

1 Tuncer M: Significance of cancer in Turkey, the burden of disease and cancer control policies; in Tuncer M (ed): Cancer Control in Turkey. Ankara Onur Press, Health Ministry Publication 2008;74: $5-9$

2 Ozmen V: Breast cancer screening and registration programs in Turkey; in Tuncer M (ed): Cancer Control in Turkey. Ankara, Onur Press, Health Ministry Publication 2008;740:335-343.

3 Schottenfeld D, Nash AG, Robbins GF, Beattie EJ Jr: Ten years results of the treatment of primary operable breast carcinoma: a summary of 304 patients evaluated by the TNM system. Cancer 1976; 38:1001-1007.

4 Fisher B, Bauer M, Wickherham L, Redmond C, Fisher E: Relation of number of positive axillary nodes to the prognosis of patients with primary breast cancer. Cancer 1983;52:1551-1557.

$\checkmark 5$ Perou CM, Sørlie T, Eisen MB, van de Rijn M, Jeffrey SS, Rees CA, Pollack JR, Ross DT, Johsen H, Akslen LA, Fluge O, Pergamenschikov A, Williams C, Zhu SX, Lønning PE, Børresen-Dale AL Brown PO, Botstein D, et al.: Molecular portraits of human breast tumours. Nature 2000;406:747752 .
6 Hugh J, Hanson J, Cheang MC, Nielsen TO, Perou CM, Dumontet C, Reed J, Krajewska M, Treilleux I, Rupin M, Magherini E, Mackey J, Martin M, Vogel C: Breast cancer subtypes and response to docetaxel in node-positive breast cancer: use of an immunohistochemical definition in the BCIRG 001 trial. J Clin Oncol 2009;27:1168-1176.

7 Lee JS, Kim SI, Choi SY, Park HS, Lee JS, Park S, Koo J, Park BW, Lee KS: Factors influencing the outcome of breast cancer patients with 10 or more metastasized axillary lymph nodes. Int J Clin Oncol 2011;16:473-481.

8 Faneyte I, Peterse JL, Van Tinteren H, Pronk C, Bontenbal M, Beex LV, Van der Wall E, Richel DJ, Nooji MA, Voest EE, Hupperets P, Ten Vergert EM, de Vries EG, Rodenhuis S, van de Vijver MJ: Predicting early failure after adjuvant chemotherapy in high-risk breast cancer patient with extensive lymph node involvement. Clin Cancer Res 2004;10:4457-4463.

9 Başaran G, Çabuk D, Çağlar HB, Güllüoğlu B, Kaya H, Seber H, Korkmaz T, Telli F, Koçak M, Dane F, Yumuk FP, Turhal SN: Clinical outcome of breast cancer patients with N3a ( $\geq 10$ positive lyph nodes) disease: has it changed over years? Med Oncol 2011;28:726-732.
0 Koca E, Kuzan TY, Dizdar O, Babacan T, Sahin I, Ararat E, Altundag K: Outcomes of locally advanced breast cancer patients with $\geq 10$ positive axillary lymph nodes. Med Oncol 2013;30:615.

11 Ahn SG, Lee HM, Cho SH, Bae SJ, Lee SA, Hwang SH, Jeong J, Lee HD: The difference in prognostic factors between early recurrence and late recurrence in estrogen receptor-positive breast cancer: nodal stage differently impacts early and late recurrence. PLoS One 2013;8:e63510.

12 Samaan NA, Buzdar AU, Aldinger KA, Schultz PN, Yang KP, Romsdahl MM, et al.: Estrogen receptor: a prognostic factor in breast cancer. Cancer 1981:47:554-560.

13 Early Breast Cancer Trialist' Collaborative Group (EBCTCG): Effects of chemotherapy and hormonal therapy for early breast cancer on recurrence and 15-year survival: an overview of the randomised trials. Lancet 2005;365:1687-1717.

14 Mansell J, Monypenny IJ, Skene AI, Abram P, Carpenter R, Gattuso JM, Wilson CR, Angerson WJ, Dougthy JC: Patterns and predictors of early recurrence in postmenopausal women with estrogen receptor-positive early breast cancer. Breast Cancer Res Treat 2009;117:91-98. 
15 Jonat W, Gnant M, Boccardo F, Kaufmann M, Rubagotti A, Zuna I, Greenwood M, Jakesz R: Effectiveness of switching from adjuvant tamoxifen to anastrozole in postmenapausal women with hormone sensitive early-stage breast cancer: a metaanalysis. Lancet Oncol 2006;7:991-996.

16 Goss PE, Ingle JN, Martino S, et al.: Randomised trial of letrozole following tamoxifen as extended adjuvant therapy in receptor-positive breast cancer: updated findings from NCIC CTG MA.17. J Natl Cancer Inst 2005;97:1262-1271.

17 Ferguson LN, Bell J, Heidel R, Lee S, et al.: Prognostic value of breast cancer subtypes, Ki-67 proliferation index, age, and pathologic tumor characteristics on breast cancer survival in Caucasian women. Breast J 2013;19:22-30.

18 Mark HF, Aswad B, Bassily N, Taylor W, Brown S, Sun CL, Samy M, Zolnierz K, Wong E, Bland KI, Hsu PH: HER-2/neu gene amplification in stage IIV breast cancer detected by fluorescent in situ hybridization. Genet Med 1999;1:98-103
19 Romond EH, Perez EA, Bryant J, Suman VJ, Geyer CE Jr, Davidson NE, Tan-Chiu E, Martino S, Paik S, Kaufman PA, Swain SM, Pisanksy TM, Fehrenbacher L, Kutteh LA, Vogel VG, Visscher DW, Yothers G, Jenkins RB, Brown AM, Dakhil SR, Mamunas EP, Lingle WL, Klein PM, Ingle JN, Wolmark N: Trastuzumab plus adjuvant chemotherapy for operable HER2-positive breast cancer. N Eng J Med 2005;353:1673-1684.

20 Slamon D, Eiermann W, Robert N, Pienkowski T, Martin M, et al.: Adjuvant trastuzumab in HER2positive breast cancer. N Engl J Med 2011;365: 1273-1283.

21 Moja L, Tagliabue L, Balduzzi S, et al.: Trastuzumab containing regimens for early breast cancer. Cochrane Database Syst Rev 2012;(4):CD006243.

22 Dent R, Trudeau M, Pritchrad KI, Hana WM, Kahn HK, Sawka CA, Licley LA, Rawlinson E: Triple negative breast cancer: clinical features and patterns of recurrences. Clin Cancer Res 2007;13: $4429-4434$.
3 Hernandez-Aya LF, Chavez-Macgregor M, Lei X, Meric-Bernstam F, Buchholz TA, Hsu L, Sahin AA, Do KA, Valero V, Hortobagyi GN, GonzalezAngulo AM: Nodal status and clinical outcomes in a large cohort of patients with triple-negative breast cancer. J Clin Oncol 2011;29:2628-2634.

24 Goldhirsch A, Winer EP, Coates AS, Gelber RD, Piccart-Gebhart M, Thürlimann B, Senn HJ; Panel members: Personalizing the treatment of women with early breast cancer: highlights of the St Gallen International Expert Consensus on the Primary Therapy of Early Breast Cancer 2013. Ann Oncol 2013;24:2206-2223.

25 Schiffman SC, McMasters KM, Scoggins CR, Martin RC, Chaqpar AB: Lymph node ratio: a proposed refinement of current axillary staging in breast cancer patients. J Am Coll Surg 2011;213: $45-52$. 